\title{
Factors affecting the uptake of cryoprotective agents by fish eggs and embryos
}

\author{
P. ROUTRAY ${ }^{1}$, T. SUZUKI ${ }^{1}$, CA. STRÜSSMANN ${ }^{2}$ and R. TAKAI ${ }^{1}$ \\ ${ }^{1}$ Deparment of Food Science and Technology. (routray30@yahoo.co.in) and ${ }^{2}$ Department of Aquatic Biosciences, Tokyo University of \\ Fisheries, Konan 45-7, Minato-Ku, Toko 108-8477, Japan
}

KEYWORDS: Cryoprotective agent, DMSO, Egg and Embryo, Medaka, Pejerrey

\section{INTRODUCTION}

Cyopreservation of fish eggs and embryos has not been accomplished yet and one of the major reasons seems to be the insufficient impregnation with cryoprotective agents ${ }^{1-3)}$ The complex stucture of these materials, inchuding their lange size, thick chorion, membranobound compantmentalization, and lange amount of yolk, is an obstacle to the uptake of permeating cryoprotectants such as dimethyl sulphoxide (DMSO). ${ }^{4}$ Likewise, little is known about the biological and physical factors that affect membrane permeability in fish egg and embryos In this study, we evahuated the suitability of eggs and two embryo stages for cyoprotectant impregnation and the feasbility of manipulating the temperature, hydrostatic pressure, and the osmotic conditions duming impregnation to promote the uptake of DMSO by fish eggs and embryos.

\section{MATERIALSAND METHODS}

Eggs and embryos of metaka (Oryzias latipes) and pejemey (Odontesthes bonariensis), two freshwater species that spawn relatively lange demersal eggs, were used in this study. Unfertilized egos were collected by gentle stripping the abdomen (pejerrey) or by dissection (medaka). Embryos were obtained by allowing the females to spawn naturally in the presence of males. After collection, normally developing embryos were selected and incubated until the desired stage. To conpare the uptake of DMSO by the different materials, $10-30$ unfertilized eggs, 8 - ell ( $2 \mathrm{hr}$ ) and eyed (5-6 days) embryos of medaka were immersed for $1,3,5,10$, 15 and $20 \mathrm{~min}$ in a 12M DMSO solution in Yamamoto ringer. After impregnation, the intemal DMSO concentetion $\left(\mathrm{C}_{\mathrm{n}}\right)$ of $5-8 \mathrm{eggs}$ or enbyos per group was analyzed by high peformanoe liquid chromagathy (HPLC) following the methods of Suaki at al ${ }^{\text {S) }}$ The remainingegssandembryoswereused forviablity estimation. Unfertilized egs were inseninated and viablity wasscured 6 hrafteractivation in fresh water. Survival of embryos was estimated after incubation for 10-11 days. The same protocols were used to investigate the effects of the temperature, hydrostatic pressure, and osmotic conditions during impregration on cryoprotectant uptake. The influence of temperature was examined by impregnating 8-cell pejeney embryos in $15 \mathrm{MDMSO}$ at temperatures of 0,5 , and $20{ }^{\circ} \mathrm{C}$. Unfertilized eggs and eyed embryos of medaka were impregnated with $25 \mathrm{M}$ DMSO in a pressure vessel under 0 and $50 \mathrm{~atm}\left(\right.$ at $20^{\circ} \mathrm{C}$ ) to investigate the effect of hydrostatic pressure. For osmotic manipulation, 8-cell pejemey embryos were first partially dehydrated for 1 or $3 \mathrm{~min}$ in a $1 \mathrm{M}$ solution of the low permeating disaccharide trehalose and then impregnated with 1.2M DMSO. Each experiment was repeated 34 times. The significance of the differences in $C_{n}$ between experimental and controls grous was analyzed by ANOVA. Fetilizationsurvival res were compared with the Yates'onnimuity ouneded Chisquare test.

\section{RESULTS}

The initial uptake rate and maximum $\mathrm{DMSO} \mathrm{C}_{\mathrm{in}}$ were higher in mecklka embryos than in egos and inceased with enbryonic developmert (Fig 1A). However, the $C_{n}$ of eyed embyos remained constart after $5 \mathrm{~min}$ Vability rates weeappoximately similarn thetheegrous Theuptake of DMSO and viability of 8cell pejerrey embryos were directly and inversely proportional to the impregration temperature, respectively (Fig 1B). Elevated hydrostatic pressure promoted DMSO uptake but caused rapid loss of viability in unfertilized eggs of medaka; in contrast, it had no measurable effect on eyed embryos (Fig 1C). Partial dehydration of 8-cell pejemey embryos in trehalose solution prior to impregnation significantly increased the DMSO $\mathrm{C}_{\mathbf{n}}$ in comparison to untreated controls without any significant effect on the survival rates (Fig. 1D). 


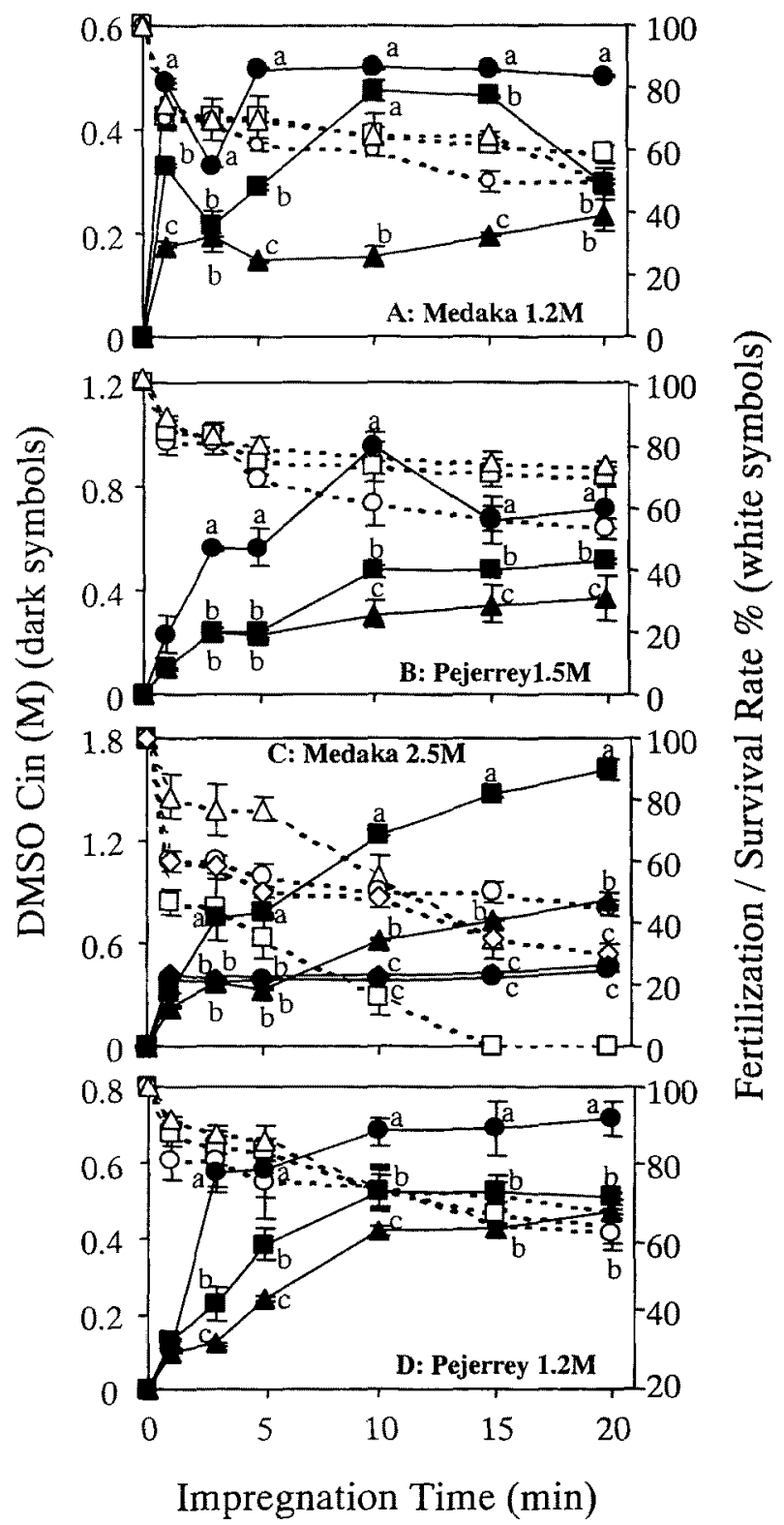

Fg 1 Effects of various factors on the uptake of DMSO $\left(\mathrm{C}_{\vec{n}}\right.$ dark symbols $)$ and fetilizationisurvival rates (white symbols) of fish eggs and embryos. The species andDMSOconoentraion during impregation are shown in the panels. Data shown as mean $\pm \mathrm{SE}$; comesponding values with different letters vary significantly

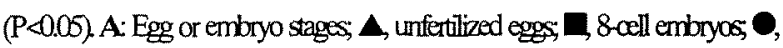
eyed embryos. B: Temperature; $\triangle 0^{\circ} \mathrm{C} ; 5^{\circ} \mathrm{C} ; 20^{\circ} \mathrm{C}$ C: Hydrastatic pressure; $\bullet$, eyed enbryo, 0 am; $\theta$, eyed embryo, 50 arm; $\boldsymbol{\Delta}$, unfertilized egg 0 am; unfertilized egg $50 \mathrm{~atm}$;. Osmotic conditions; $\mathbf{A}$, control; $\mathbf{Z}, 1 \mathrm{~min}$ dehydration; 3 min dehydration

\section{DISCUSSION}

This study showed that unfertilized eggs took up less cryoprotectant than embryos during impregnation with $1.2 \mathrm{M}$ DMSO (at 0 atm), even though the former are structurally simpler than the latter. However, this trend was reversed under a DMSO concentration of

25M and even more so at 50 atm. The exact reason

for this difference in uptake between eggs and embryos acoording to the impregnation concentration is unknown but it could be related to a lower tolerance of the eggs to $\mathrm{DMSO}^{4}$ and the passive entry of cyoprotectant due to damaged membrane sites and non-viable cells. Differential tolerance and loss of viability could be responsible also for the dramatic increase in DMSO uptake in the eggs under $50 \mathrm{~atm}$. However, eggs impregnated under 50 atm for 3-5 min showed higher

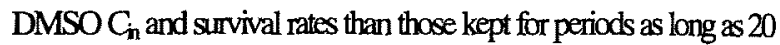
min but at $0 \mathrm{~atm}$ In 8 cell embryos, elevated hydrostatic pressure improved DMSO uptake without loss of viability (P. Routray et al, umpublished results). Thus, from the point-of-view of impregnation, different stages seem to differ in suitability for cryopreservation. Also, hydrostaic pressme seens to aller membrane pemeability in fish eggs and embryos but isseffectsarestage-andprobably alsoconcentraiondependent. The other examined factors impregnation temperature and osmotic manipuktion, had a clear effecton the uptake of DMSO. The propational uptake of DMSO with temperature by 8 cell enbryos resembles the improved uptake by mouse andhemembryosat $30^{\circ} \mathrm{C}$ incomparion to $0 \mathrm{or}-3^{\circ} \mathrm{C}^{9}$ Asexpected, partial dehydration of the embryos prior to impregnation greatly enhanced the uptake of DMSO. It was assumed that an comotic differential caused by dehydration might facilitate the uptake of watabome DMSO duming impregnation. Thus, the results of this study indicate that hydrostaic presere, temperature of impregration and the osmoticonditions of the materalsconbe manipulted to increase the uptake of cyoproctant and pethos lead to sucoessfil cryopreservation of fisheggsandembryos.

\section{REFERENCES}

1. Bart A New approaches in cryopreservation of fish embryos in: Tessch TR, Mazk PM (eds), Cryopreservation in Aquatic Species. Baton Rouge, World Aquaculture Society, USA, 2000; 179-187.

2. Chao NH, Liao IC. Cyopreservation of finfish and shelfish gametes andembryos Aquaculume 2001; 7:161-189.

3. Gwo J-C. Cyopreservaton of eggs and embryos from aquatic organisms. In: Teesch TR, Mazk PM (eds), Cryopreservation in Aquatic Species. Baton Rouge, World Aquaculture Society, USA, 2000, 211-229.

4. Harvey B. Cooling of embryonic cells, solated blastoderms, and intad embryos of the zebra fish, Brachydario revio to $-196^{\circ} \mathrm{C}$. Cyobiology. 1982; 19:15-19.

5. Suzuki T, Komada H, Takai R, Anii K, Kozima TT. Relation between toxicity of cryoprotectant DMSO and its concentration in several fish embryos. Fisheries Sci 1995; 61:193-197.

6. Paynter SJ, Cooper A, Gregory L, Fuller BJ, Shaw RW. Permeablitity characteristics of human oocytes in the presence of the cyoprotectant dimethylsulphoxide. Hhom Reprod. 1999, 142338-2342. 